\title{
Hipsters in the hood: Authenticating indexicalities in young men's hip-hop talk
}

\author{
P I A P I C H L E R \\ Goldsmiths, University of London, New Cross London SE14 6NW, UK \\ p.pichler@gold.ac.uk
}

\author{
N A T H A N A E L W I L L I A M S \\ nathanael@soundandmeaning.com
}

\section{A B S T R A C T}

In this article we explore the relationship between authentication and identification in the spontaneous hip-hop talk of four young London men from multi-ethnic working-class backgrounds. Whereas sociolinguistic studies of authentication and/or hip hop have frequently focused on the linguistic style of hip hoppers, this article explores hip-hop talk with a specific interest in 'cultural concepts' (Silverstein 2004). This focus allows us to discuss how the young men authenticate themselves in relation to a range of other identity performances they discuss, including the 'white posh girl's' appropriation of 'world star' hip-hop culture or the local South London gang's display of violent gangsta personas. These cultural concepts not only index various aspects of hip-hop culture but also need to be understood in relation to various aspects of larger-scale discourses, practices, and structures. (Hip hop, authentication, indexicalities, cultural concepts)*

The social construction of authenticity has received attention in a range of recent scholarly work across disciplines, including sociolinguistics, race/ethnicity, and hip hop (McLeod 1999; Cutler 2003; 2010; Reyes 2005; Scott Shenk 2007; Terkourafi 2010a; Chun 2011; Jeffries 2011; Mason-Carris 2011). This article develops existing scholarship on authenticity in both sociolinguistics and hip-hop studies with a particular focus on the indexicalities of hip hop that emerge in the spontaneous talk of four young South London men from multi-ethnic working-class backgrounds. The significance of hip hop is evident throughout the various selfrecorded get-togethers of the young men, be this in their explicit talk about hiphop artists and followers, or in their stories about local gangs, white posh girls living on rough estates, and hipsters moving into the hood. This article explores 
the indexicalities of (and beyond) hip hop on the basis of the many cultural concepts (Silverstein 2004) that are employed by the young men as a central means of authentication (Bucholtz \& Hall 2005).

McLeod highlights the discursive construction of authenticity in hip hop in his 1999 study. He concludes that 'Keepin' it real and various other claims of authenticity do not appear to have a fixed or rigid meaning throughout the hip-hop community' (1999:139). On the basis of hip-hop lyrics, magazine articles, postings to internet discussion groups, and interviews with artists and a couple of fans, he identifies six dimensions (or interpretations) of hip-hop authenticity. Many of the dimensions that McLeod (1999:139) discusses feature in subsequent research on hip-hop authenticity as we show below-above all, the dimension of 'staying true to yourself' rather than 'following mass trends', being close to 'the street' rather than 'the suburbs', but also being 'black' rather than 'white', 'hard' rather than 'soft', orienting to 'the underground' rather than 'commercialism', and 'the old school' rather than 'mainstream'. McLeod argues that these authenticity claims serve hip-hop community members as a means of protecting 'their culture' against 'the threat of being erased and transformed into something that is undesirable', for example, by (inauthentic) 'outsiders' (1999:148). However, subsequent work suggests that questions about what constitutes authentic hip-hop 'culture' and what differentiates insiders from outsiders require answers that take into consideration local contexts as much as hip hop as a global phenomenon.

Much of this work presents the African American urban or 'street' experience as central to the history of hip hop (e.g. McLeod 1999:140-42; Cutler 2003:213, 2010:301; Alim 2006:122). However, not all accounts of hip-hop authenticity position whiteness as inauthentic or fake, particularly and unsurprisingly for white or non-US hip hoppers (e.g. Alim 2006:10-11; Alim, Ibrahim, \& Pennycook 2009; Jeffries 2011:138). Jeffries (2011) conducted interviews with young US (Boston) hip-hop performers and followers as part of his research project on hip hop. He concludes that although his interviewees tended to subscribe to a rather essentialist view of authenticity (2011:147), analysis of their varying interpretations of authenticity challenges the idea that authenticity in hip hop is static and consistent. In opposition to McLeod's categories, Jeffries found that 'race-based concerns about authenticity are completely absent from white respondents' discussions of the "keep it real" phenomenon' (2011:140). What was important to all respondents was instead that 'being oneself means embracing one's racial and ethnic identity' (2011:139). Cutler's (2003, 2009, 2010) sociolinguistic work on hip-hop authenticity, which is introduced in more depth below, supports Jeffries' findings, at least for what she calls 'core white hip hoppers'.

That neither an urban African-American upbringing nor personal experience of tough street culture, or for that matter 'thug life', are undeniable prerequisites for authentic hip-hop identities should not come as a surprise if one considers the global flow of hip hop, which, as has been documented in recent research, cannot be attributed to globalisation and English imperialism alone (e.g. see 
recent edited collections such as Alim et al. 2009; Terkourafi 2010b). Pennycook \& Mitchell (2009:27) make this argument poignantly when they argue that 'local Hip Hop can be both part of international popular culture while at the same time articulating local philosophies of global significance'. Thus Alim (2009a) prefers to speak about hip-hop cultures in the plural, and recent research captures the complexity and diversity of meanings of authenticity for hip hoppers (Alim et al. 2009; Terkourafi 2010b).

Whereas hip-hop studies based on interview data from hip-hop consumers and analysis of hip-hop media frequently aim at an understanding of what constitutes authentic hip-hop performances and performers (e.g. Jeffries 2011:134), our own study takes a sociocultural linguistic approach to the analysis of authenticity in so far as it aims to investigate how speakers 'authenticate' their identities (see Bucholtz \& Hall 2005) in relation to various aspects of hip-hop culture(s). Our summary of sociolinguistic studies on hip hop and/or authenticity below shows that most have been driven by an interest in the different linguistic strategies employed by speakers and performers to stylise their identities. Frequently this has been in the context of studies on crossing, that is, studies of language users employing varieties of language that are not thought to belong to them, for example, the use of African American Vernacular English (AAVE) by white and/or middle-class Americans and or the use of AAVE and/or the code-switching practices of, perhaps, German, Japanese, or Tanzanian hip hoppers (see for example recent edited collections by Alim et al. 2009 and Terkourafi 2010b). A limited number of studies have approached the topic of hip-hop authenticity with an analytic focus on discourses/ideologies rather than linguistic style (Cutler 2003, 2010), and even fewer studies have investigated what Androutsopoulos (2009:44) calls the 'third sphere' of hip hop, that is, interaction 'among Hip Hop fans and activists' (for an exception see Roth-Gordon 2009).

In this article we present the talk of a group of young men from London whose shared background as multi-ethnic and working class, together with their identification as musicians, in many ways allows them to highlight their own authenticity in relation to hip-hop culture. Indeed the data extracts we discuss here show that in their self-recorded talk aspects of hip-hop culture and identities are made relevant throughout by the young men in many different ways, and well beyond the discussion of actual hip-hop music or hip-hop artists. Our focus is on how this talk allows the young men to position themselves in relation to a range of other (classed, raced) identity performances they discuss, be this the identity of the 'white posh girl' whose appropriation of 'world star' hip-hop culture is positioned as inauthentic, or the practices of local South London gangs whose display of violence and criminality appears like a homage to gangsta rap video personas to the young men in the group. We approach the analysis of the practices and positions the young men adopt with a focus on the 'cultural concepts' (Silverstein 2004), that is, stereotypic meanings, indexed by words and expressions in the young men's talk. In our analysis we focus on terms and expressions that not only index, or, in other words 'invoke' or 
'point to' various aspects of hip-hop culture, but that also need to be understood in relation to 'a macrosociological order of interdiscursivity immanent in microcontextual discursive interactions', as Silverstein (2004:640) reminds us. Thus, when the young men talk about 'white girls from The Hills', or 'hipsters moving into the hood', or, in reference to the local gang, 'dhem man will spray the matic out da Porsche', they not only evaluate the authenticity of their own and others' identity performances in relation to hip-hop culture, but hip-hop culture in itself is presented as indexical of various aspects of larger-scale practices and structures. This often indirect relationship between linguistic forms and social meaning, and between different levels of indexicality, is at the core of indexicality studies (e.g. see Ochs 1992 on direct vs. indirect indexical relations; Silverstein 2003 on different orders of indexicality; and Bucholtz \& Hall's (2005) positionality and indexicality principles) and is central to our own exploration of spontaneous hip-hop talk.

In the remainder of the article we first introduce recent work on authenticity in sociolinguistics. We then offer further discussion of Silverstein's work on cultural concepts, which, supported by a focus on the interactional negotiations of these cultural concepts, informs our subsequent analysis.

\section{A U T H E N T I C I T Y I N S OCIOLINGU IS T I C S}

Sociolinguistic research has challenged the view that authenticity is 'an inherent essence', instead preferring to view authenticity as an ideological construct and focusing on 'authentication as a social process played out in discourse' (Bucholtz \& Hall 2005:601). This allows for a shift of analytic focus from what does or does not constitute authentic selves, to an interest in the 'authenticating practices' (Bucholtz 2003:403) employed by speakers to construct themselves and each other as (in)authentic. This practice-based approach to authenticity that is at the core of Bucholtz's concept of 'authentication' is also captured by Coupland's (2003:428) 'authenticity in performance', which views authenticity as 'earned rather than credited'. Language users can highlight the genuineness or artifice of either their own or others' practices and performances, thereby either 'authenticating' or 'denaturalizing' identity performances (Bucholtz \& Hall 2005:601). These processes can be observed particularly well in sociolinguistic research on crossing, that is, in instances where speakers (momentarily) switch into a style of language that 'is not generally thought to belong to [them]' (Rampton 1995:280). Hewitt's early work on the use of creole by white young speakers in the UK in 1986, followed by Rampton's ethnographic exploration of young people's crossing into a variety of languages, including Panjabi, as well as Bucholtz's (1999) ethnographic study of white European Americans employing African American Vernacular English (AAVE) in the US are some of the most prominent examples of this work.

Although research on instances of crossing shows that there is a 'distinct sense of movement across social or ethnic boundaries' (Rampton 1995:280), there is no suggestion that speakers are trying to 'pass' as a member of a different ethnic (or even 
racial) group (e.g. see Reyes 2005). In fact, trying to 'pass' is evaluated negatively by most speakers (e.g. Cutler 2003:226). Other sociolinguistic research explores more overt attempts of speakers' construction of (in)authentic ethnic or racial identities. For example, Scott Shenk's work on authenticating 'discourses' shows how authentic ethnic identity is constructed in the talk of bilingual Mexican-American college students in relation to ideologies about 'purity of bloodline, purity of nationality, and Spanish linguistic fluency' (Scott Shenk 2007:195). Speakers adopt a range of overt authenticating stances or 'moves' to index authentic Mexican identity, or challenge the performances of one another, for example, highlighting their own authenticity by positioning somebody else as inauthentic (Scott Shenk 2007:198).

Even explicit ethnic and racial categories employed by speakers in their authenticating talk can index various intersecting levels of meaning, as Chun's (2011) work in a diverse high school in Texas demonstrates. Students employed labels such as 'black' and 'white' frequently in their talk to signal racial (in)authenticity, but meanings were negotiated in speakers' interaction in relation to 'local ideologies of race, gender, class and authenticity' (Chun 2011:404). The intersectionality of race with other identity categories that emerged from our own data is evident in some of the labels used by Chun's high school students when commenting on what they perceived to be racially inauthentic performances, as for example in the term prep girl, which is interpreted as 'an embodiment of middle-class white hyperfemininity', or ghetto boy, which is positioned as 'an embodiment of working-class black hypermasculinity' (Chun 2011:413). The dynamic and local negotiation of the meaning of explicit ethnic labels is also evident in Kang's (2004) study of the self-categorising talk of young American Korean counsellors in a holiday camp, and although Kang does not explicitly comment on issues of authenticity, it is clear that the speakers' usage of labels such as 'Korean', 'American', or 'Korean American' was motivated by their desire to authenticate themselves in the context of the Korean holiday camp.

Cutler's work deserves to be discussed in some more depth as it explores authenticity and authenticating processes from a sociolinguistic perspective with a special interest in hip hop (Cutler 2003, 2009, 2010). Cutler's research explores the linguistic style of hip-hop artists and followers, that is, on Hip-Hop Speech Style or HHSS (cp. also Hip Hop Nation Language or HHNL; Alim 2006). Cutler combines this focus, however, with an interest in authentication, particularly and more explicitly so in her more recent work. Her work focuses mostly on young people whose ethnic and social class background (e.g. as white and/or middle class) requires them to do considerable authenticating work as they would otherwise be perceived to be too removed from the 'urban African American experience [that] is central to its message and reflective of the fundamental role African Americans have had in its creation' (Cutler 2003:213).

HHSS refers to speakers' individual usage of verbal (dialects, registers) and nonverbal (fashion and gestures) forms of expressions. One example of HHSS usage is presented in Cutler's early work on a white, middle-class, private-school educated teenager from one of the wealthiest, white neighbourhoods in New York City. Despite 'Mike's' background he increasingly adopted aspects of stereotypical 
African American urban street culture, including a 'tag name', experimented with drugs, joined a gang, took part in violent conflicts and clashes with the police, and was finally expelled from his private school (Cutler 2009:300). He increasingly used AAVE phonology (e.g. self-correcting from ask to aks or adopting postvocalic $r$-lessness) and vocabulary/slang (e.g. wassup/'ssup, the shit, and expressions such as brother, bro, nigga, kid, and some syntactic features such as habitual BE, for example, you know sometimes how they be wise asses; Cutler 2009:301-305). What initially started as more fleeting attempts at crossing into AAVE later developed into a form of 'stylization' that, Cutler reminds us, does not constitute an attempt to 'pass for a member of the imitated group'; instead, 'HHSS offers an array of linguistic resources for expressing identities rooted in some degree of affiliation with Hip-Hop culture' (Cutler 2009:308). Cutler's subsequent work, however, shows that the closer to 'core' hip-hop culture young white Americans were, the more at ease they were with topicalising race, and the less concerned they were about authenticating themselves with the help of other stylistic markers (Cutler 2003, 2010). Moreover, Cutler's (2010) work on the US reality TV programme The White Rapper Show captures competing versions of authenticity at play: whereas some competitors authenticate by highlighting closeness to African-American street culture, others authenticate by signaling honesty about their own (white, middle-class) background.

Cutler's work is of particular importance to the current study, as it is driven by a sociolinguistic interest in processes of authentication in relation to hip hop. Our own data contains many examples of linguistic features that have been associated with HHSS in the work of Cutler $(2003,2009)$ and others, including, most prominently Alim (e.g. 2009a, 2009b). However, our data also shows how difficult it is to differentiate between HHSS and the kind of multi-ethnolect spoken by young Londoners in areas of high immigration, ethnic/racial diversity, and economic deprivation, as described by Cheshire, Kerswill, Fox, \& Torgersen (2011) in their work on Multicultural London English or MLE. Throughout the recordings, Les, as well as some of the other speakers in the group, uses features of pronunciation such as dey and dem instead of they and them; yout instead of youth; negative concord (including ain't) as in there ain't no niggas there; lexical items including niggas, hood, bruv, or man; or phrases such as do you feel me. Although it is possible to trace the origin of many of these features to what Alim (2006: 101) calls the 'Black Language Space' or BLS, whose relationship with HHSS is evident, we consider it to be problematic to interpret them as unquestionable indices of hip-hop culture affiliation in everyday situations of MLE or any other urban multi-ethnolectal language use (but see Brunstad, Røyneland, \& Opshal 2010 for an investigation of the relationship between HHSS and urban multi-ethnolectal language use).

Our own study aims to demonstrate the value of moving the study of authenticity in relation to hip hop from a consideration of (the indexicality of) linguistic style towards a focus on discourse and ideological meanings. Although our data contains many features of language style that support the young men's authenticating work, 
the main aim of this article is to explore the use of 'cultural concepts' (Silverstein 2004) as a significant resource for authentication in the young men's hip-hop talk.

\section{U L T UR A L C ONCEPT S}

In this article we approach the relationship between authenticity, authentication, and identification with a specific focus on 'cultural concepts' (Silverstein 2004) that are invoked in the spontaneous talk of the four young men. Silverstein (2004:638) uses the term cultural concepts to refer to stereotypic meanings that emerge in spoken interaction, indexed by certain words and expressions. These cultural concepts in turn index or invoke shared and in part unconscious sociocultural knowledge and allow speakers to position themselves in relation to these concepts and to one another (2004:632-33). As Silverstein argues,

[t]he use of certain words and expressions at a particular point in discursive real time therefore does more than contribute straightforwardly to denotational text. It marks (indexes) the user as a member of a certain group or category relative to the groups or categories of persons, things, etc., already in play through contextual and co-textual indexicalities up to that point... (Silverstein 2004:633)

While discussing examples from a range of linguistic and cultural contexts, including the cultural concepts of 'edibility' as indexed by Thai villagers in relation to 'lexically nameable faunal types' (2004:635), Silverstein focuses especially on cultural concepts that index what he calls 'First World elite identit[ies]' (2004:649). These identities include that of the 'old Jesuit boy', indexed in an exchange between two male US graduate students when they discuss their undergraduate experiences, or that of the 'wine connoisseur' in the ritual discourse of wine tasting. The interpretation of these cultural concepts requires knowledge that goes considerably beyond that of the denotational meaning of words and expressions and cultural knowledge that, as Silverstein points out, is unlikely to be shared by outsiders or 'non-cognoscenti' (2004:544), such as international audiences (or readers or speakers) who have not been exposed to the same 'stereotypic knowledge schemata' (2004:633). For example, when the two students mention the names of the 'schools', that is, universities, they attended as Georgetown and Loyola (of Chicago), specific cultural knowledge is necessary to understand that both of them are Jesuit universities, and, moreover, that Georgetown ranks more highly than the other. By deploying these words the young men therefore index not only their identities as university graduates and as 'Jesuit boys', but they also index a status difference (Silverstein 2004:632). Similarly, by using terms and the overall register of what Silverstein (2004:640) calls oinoglossia or 'wine talk', speakers not only index their connoisseurship but also, at a higher order level of indexicality, their elite (consumer) lifestyle and identity.

In this article we use Silverstein's cultural concepts to consider a very different type of 'connoisseurship'. The young men's talk about hip hop would certainly not have counted as an example of speakers indexing 'distinction' in Bourdieu's (1984) classification of lifestyles and (musical) tastes (but see Jeffries 2011:118 for a brief summary of critical accounts of Bourdieu's theory of taste). In the extracts of talk 
we present here, a very different cultural capital is at stake, and the identities constructed cannot be understood as 'elite'. Nevertheless, the speakers' talk is rich in cultural concepts, that is, words and expressions that index cultural knowledge (e.g. knowledge about hip hop, social class divisions, ethnic boundaries, raced identities, and consumerist discourses) and that allow participants to 'deploy this knowledge like identity-linen by hanging it out interpersonally and intersubjectively' in a specific interactional moment (Silverstein 2004:633).

Silverstein highlights the importance of considering indexicality in 'the microcontext of interaction' (2004:638-39). He shows how in interaction speakers use cultural concepts to 'organise information into a conceptual metrics, in addition to the explicit poetics of metrical repetition, constructional parallelism, and lexical ligature' (2004:629). In our own discussion of hip-hop authenticity, this conceptual metrics is clearly noticeable, for example, when cultural concepts such as 'the hood' and 'world star hip hop' are contrasted with others such as 'hipsters' and 'white posh girls from The Hills'. Our own interest in the 'microcontext of interaction' does not only allow us to explore the indexical meanings of cultural concepts as invoked by the speakers in specific moments of interaction, but also extends to some of the details of the interactional negotiations around the young men's positioning in relation to these cultural concepts and to one another.

\section{THE D A T A}

The four members of the group — Les, Joe, Tim, and Nath—describe themselves as ethnically mixed men in their early to mid twenties who consider music-making to be their primary vocation. Joe's mother and father are both of Filipino descent. Tim's father is from Jamaica and his mother is from Wales; however, both parents have lived in England for most of their lives. Les is of mixed Jamaican and English descent with his father now living in Jamaica. Nath is of Caribbean/English descent and grew up in foster care in a working-class area of Birmingham. All of the participants are from working-class backgrounds with parents in manual labour or service sector jobs. Tim, Les, and Joe grew up in south London and have spent their adolescent and young adult lives socialising in Peckham, a traditionally poor working class and now ethnically highly diverse area in south London. These three speakers describe their life in Peckham as involving fairly frequent criminality and violent altercations. The data show that Les frequently assumes the most insider position when the group talks about criminality, foregrounding his brother's membership in one of the most notorious South London gangs (see extract (4)). Les was unemployed at the time of the recording, whereas Joe had recently found employment and Tim was about to begin an undergraduate music degree. Nath and Tim were flatmates, and Nath got to know Les and Joe through Tim. Nath is the co-author of this article and the only group member whose name has not been changed to preserve anonymity. Nath's original purpose for collecting the data while he was an MA student in London was that he felt that there was a lack of 
research on spontaneous conversational data from ethnically mixed young British men like himself. He did not commence data collection with an a priori interest in hip hop and the focus of this article was determined by the vast amount of time that the group ended up dedicating to the topic. However, the young men also talked about many other topics, including fatherhood (Les is the father of a baby son, and Joe is the father of an infant daughter), family relations, the U.S., language use, social class divisions, and race. During the recordings the speakers were frequently engaged in some other activities, mostly listening to music but also watching videos or looking at images on their phones. Nath recorded the conversations (with the full knowledge of the group) in various locations in South London between December 2012 and July 2013, some at Nath's house (in the basement), some in Tim's ${ }^{1}$ kitchen, and some in Joe's studio in Brixton. Total recordings amounted to five hours, fifteen minutes. The authors remain in contact with the group, which, for example, has resulted in a title change for this article upon the request of the group. ${ }^{2}$

\section{A N A L Y S IS}

A considerable amount of the group's hip-hop talk occurred in relation to talk about race and social class. There was a lot of talk about the global appeal of hip hop as well as about individual hip-hop artists, partly in relation to their work, but also about certain artists 'selling out' by signing 'million dollar endorsement deals'. Hip hop was also discussed in relation to appropriate behaviour in front of children, and both the young fathers in the group spoke about trying to prevent their children from being exposed to what they considered inappropriate hip-hop language. From the extensive amount of hip-hop talk recorded by the group, we were able to select only a few extracts. We focus in particular on stretches of hip-hop talk capturing the young men's authentication in relation to indexicalities of class, race, and place, but we also include an extract that shows the young men's positioning in relation to indexicalities of gangsta and thug life.

\section{N D E X I C A L I T I E S O F C L A S S, R A C E, A N D} P L A C E

The following extract contains some of the group's talk about World Star Hip Hop (WSHH) that all of the four participants are familiar with and enjoy. WSHH is a website that features a collection of daily updated videos including rap battles, hip-hop videos, poetry, sports, comedy, interviews, and trailers, as well as user-generated content that contains a weekly fight compilation that is made from the videos that users send in. In the videos it is common for the person videoing to shout 'World Star' when they have filmed something they consider worthy of being uploaded. Most of the videos feature images of working-class youth from inner-city American and British locations. However, there are increasingly more videos of altercations outside these environments. 
The transcription ${ }^{3}$ begins just after the group have compared the global appeal of World Star Hip Hop with a British programme called Spiff TV, which is mentioned a moment earlier.

(1) You're not rachet pussy

1 Les: it's not like= =world star's sick

Joe: $\quad$ not as big obviously World Star's like global boy= $\quad$ (scream) 'World Star'

2 Les: I seen some I seen some girls

Nath: they've got a good they've got a good good model (.) adverti-

3 Les: there was some girls fighting yeah and there was these white girls they looked like posh

4 Les: white girls from *The Hills yeah (.) and they were going 'WORLD STAR WORLD STAR

Joe: $\quad \mathrm{mm}$ yeah \{laughs\}

Nath: $\quad$ \{laughter\}

* 'The Hills' is an MTV show on white upper middle-class girls from California

5 Les: WORLD STAR WORLD STAR' \{high pitched $\}$ and they were going crazy I was

Nath: $\quad$ \{-----continuing laughter ------$\}$

6 Les: *rah everybody's watching world star Miley Cyrus

Nath: $\quad$ \{laughing/oh sh-

Joe: $\quad * *$ bruv and imagine America this is here

*rah = equivalent of wow or woah

**bruv = version of 'brother', equivalent of mate, dude

7 Les: watches it what's the matter with her

Joe: $\quad$ yeah $*$ twerking like a mutha fucka

*twerking = thrusting, sexually provocative hip movements (mostly as part of dance)

8 Les: $\quad$ \{kisses teeth\}

Joe: $\quad$ she's gone nuts (.) doing shit with Snoop Dogg and that

Nath: $\quad$ Miley Cy-

9 Les: $\quad$ she said she's * ratchet pussy that's what she said

Nath: I seen see- her bent over do-

*ratchet = 'ghetto', 'trashy', 'annoying'; when referring to a female it is similar to skank

10 Joe: she said she's ratchet /pussy (.) you're not ratchet pussy you're the daughter

11 Nath: ahh

Les:

that's what that's what ...

Joe: of the guy that sang a- achy breaky heart 
In this extract, the group invoke a number of cultural concepts to indicate their consensus on what they consider to be (in)authentic hip-hop identities. In staves $2-4$, Les provides an increasingly more elaborate description of what he has seen on WSHH; "these girls fighting", "white girls", "posh white girls from The Hills". The items on this list are contrasted with "World Star (Hip Hop)" in stave 4, that is, "posh white girls from The Hills" are set in opposition with World Star Hip Hop culture. This means that authentic World Star Hip Hop culture is presented as both raced (in opposition to 'white') and classed (in opposition to cultural concept of 'The Hills', i.e. suburban - Californian - upper middle class).

The authentication through cultural concepts is supported by the young men's use of certain features of verbal (and nonverbal) style, including the use of lexical items such as rah and bruv (stave 6), nonstandard plural there was (stave 3), and nonstandard past tense I seen (staves 2, 9). Several of these features could be seen to index HHSS (Hip Hop Speech Style) or Black English Vernacular (BEV), as, for example, the instance of teeth kissing to signal exasperation about Miley's behaviour in stave 8 (e.g. see Cutler 2003:223). Bruv is a UK form of bro or brother, used as a synonym of mate. Although bruv can be linked to brudda in creole and reference to 'brothers' is common in hip hop, use of the term is also extremely common outside of hip hop, for example, among South or East London (white) males. The term rah is probably derived from Jamaican rahtid and used as an exclamation instead of oh shit or wow, but it can also be used as a greeting to express solidarity. Rah, and even more bruv, are now much more widespread in UK youth vernacular, and the same is of course true for many of the other nonstandard tense or plural markers. It would therefore be problematic to conclude that these features, in isolation, necessarily index closeness to hip-hop culture. The indexical links of the cultural concepts to hip-hop culture in this extract are, by contrast, very clear, and they can serve to provide anchorage to many of the features of vernacular language style in this extract.

In staves 6-7, "Miley Cyrus" is set up by the group in a similar opposition to WSHH as the "white girls from The Hills". Miley Cyrus, a popular pop star who rose to fame thanks to her leading role in the Disney series Hannah Montana, becomes a cultural concept herself at this moment of the interaction. The activities that are presented to be at odds with Miley Cyrus are "twerking like a mutha fucka" (stave 7) and "doing shit with Snoop Dogg" (stave 8). The fact that Cyrus's collaboration with a famous hip hopper does not suffice to claim hip-hop authenticity is noteworthy (as is the fact that Snoop Dogg's authenticity does not appear to suffer from the collaboration with Cyrus in the eyes of the group). Even more interesting is the fact that Miley's twerking is presented as inauthentic/inappropriate, as can be seen in Les's and Joe's responses: "what's the matter with her" and "she's gone nuts" (stave 7-8).

The group's shared understanding of why twerking and Miley Cyrus are at odds is not (and does not have to be made) explicit. Possible reasons are her class 
background, her pop-star identity, and her whiteness, or a combination of these factors. Although there is still a dearth of academic work on twerking, it is clear that the term can index (black) female hip-hop dance culture (see for example compilations of twerking clips on World Star Hip Hop). Durham (2012) writes about 'hip-hop feminism' and Weidhase (2015) describes twerking in the context of this hip-hop feminism as 'a reclaiming of the black female body and sexuality'. However, whereas race was made explicit in its opposition to WSHH authenticity in stave 3, this is not the case here. Indeed, sexualised dance/singing performances are also not accepted by the group as appropriate behaviour for young female members of their own families, as our recordings show.

What is beyond question is that the group present Miley Cryrus's appropriation of several aspects of hip-hop culture as inauthentic. The final set of oppositional pairs makes this even clearer. In stave 8 Les remarks that "she said she's ratchet pussy" and Joe repeats his remark in surprise. Ratchet is a term with clear indexical links to hip hop, and, especially in relation to gangsta rap, it indexes ghettoness. When used to refer to women, ratchet tends to be derogatory, connoting trashiness and sexual promiscuity. By calling herself ratchet pussy, Miley Cyrus is trying to claim a street or hip-hop identity that presents sexualised performance as normal or emancipatory. Clearly Les and Joe reject her self-positioning as being in any way authentically 'street'. Joe makes his rejection explicit in staves 10-11: "you're not ratchet pussy you're the daughter of the guy that sang achy breaky heart". By affiliating her with her father's class, occupation, and commercial success (Billy Ray Cyrus is a musician who rose to fame with this gentle country/barn-dance tune), Joe positions Miley Cyrus as inauthentic in her construction of an identity associated with hip-hop or street culture.

In this extract, then, concepts that are indexical of hip-hop culture, such as 'ratchet pussy', 'world star (hip hop)', and 'twerking', are presented as being in opposition with 'white girls from The Hills' and the pop star Miley Cyrus. Challenging the authenticity of others allows the speakers not only to signal their own understanding of hip-hop culture, but also to authenticate themselves. 'Understanding' hip-hop culture is extremely important in this group and is frequently linked to the 'black community' and 'black culture' by Les, as the following extract shows.

(2) Hipsters in the hood

1 Les: but like (.) in this world if we're gonna put colour on things ev- even just have (-)

Les: 'oh that's a black guy and that's a white guy yeah' $\mathrm{mmm}_{\text {Joe: }}$ then hip hop is a
Les: black thing you know dhem ones dhere because it was started in the
Nath:




\section{HIPSTERS IN THE HOOD}

$4 \quad$ Les: black community and it was created by black people through (.) the culture

5 Les: do you know what I'm saying the black culture and community black people

Nath: $\quad$ yeah

6 Les: were segregated in (.) America do you hear what I'm saying like America was

Nath: $\quad$ yeah

7 Les: segregated it's not like $=$ we live on the same block wh- and there's a white guy

Joe: $\quad$ =over here

8 Les: when you go Harlem yeah there ain't no white guy in that block

Joe: $\quad \mathrm{mhm}$

Nath: $\quad$ yeah

9 Les: in that tower block (.) now there might be like some *hipsters that moved in

*hipster = young, middle class person with a distinct fashion style

10 Les: from like (.) wherever do you know what I'm saying to like do you know what

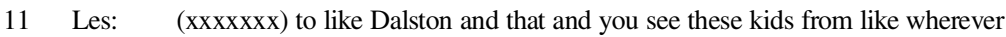
Joe: $\quad(\operatorname{xxxxxxxx})$

12 Les: and they and they're living in (.) they're living in the hood like I've been to

13 Les: $\quad$ some girl's house I know one girl (.) yeah her dad (-) is the founder of *Prada (.)

* This was not the haute couture fashion house Les mentions in the original recording

14 Les: and she lives in (.) erm War- *Warbury estate (.) (xxxx) in fucking Hackney

Nath: $\quad$ in Dalston

* the name of the estate has been changed

15 Les: (.) you know by Clapton that's like one of the roughest estate that is the

16 Les: roughest estate in East London (.) no "why do you live here" she's like

17 Les: “what's wrong with here” (-) I'm like 'are you being serious' like

Joe: $\quad$ got the (xxx)

18 Les: I used to go *link her I used to be like "I can't I can't just walk through"

*link = connect, meet, date

19 Les: lik- come out and meet me I don't walk through your ends like that by

Joe:

(XXXX) 
20 Les: myself I need you to come I need a white blonde girl to walk through with me

21 Les: because if I don't have you with me yeah $\mathrm{mm}$ these niggas are gonna think
Joe:

22 Les: I'm some *goon in their ends tryin'a get me (.) "who's dat" get on to me you

*goon = gangsta

23 Les: know what I'm saying but they don't like understand

We restrict our discussion of this very rich extract to a few main points, focusing in particular on how indexicalities of place are made relevant by Les throughout. In just the way that 'white girls from The Hills' and 'Miley Cyrus' are set in opposition to 'WSHH' and 'twerking', Les uses another set of mainly placerelated concepts to index authenticity (right column) vs. inauthenticity (left column); see Table 1.

TABLE 1. 'Hipsters in the hood'.

\begin{tabular}{|c|c|}
\hline inauthenticity & authenticity \\
\hline white guy & Harlem \\
\hline hipsters that moved in from wherever & living in the hood \\
\hline one girl [whose] dad is the founder of Prada & roughest estate in East London \\
\hline white blonde girl & in fucking Hackney... \\
\hline
\end{tabular}

The classed and raced connotations of place are particularly clear in Les's first example, in which he sets Harlem in absolute opposition to whiteness. His insider perspective of the situation in the UK allows him to see that the relationship between place and social class and/or race is more complex: the hipsters and the white blonde girl actually do live 'in the hood', that is, in rough parts and estates of London. Nevertheless, their authenticity is still challenged by Les. For Les there is something at odds here, and this something is clearly the indexicality of place/location. It is almost as if the hipsters and certainly the blonde girl are playing 'living in the hood'. This should not come as a surprise if we consider that 'the hood' is 'arguably one of U.S. Hip Hop's most visible exports, iconically linking Blackness to urban space' (Roth-Gordon 2009:65). Certainly the association between place and people is very different for the hipsters and the white blonde girl than they are for the black people living in Harlem, or "these niggas" (stave 21) in the UK, or indeed for Les himself. The physically threatening consequences of a place like this are a reality only for Les, not for the hipsters or for the blonde white girl who clearly is one of those (white privileged) people that "don't like understand" (stave 23) what it means for a black man from outside the estate to 
even briefly enter this location. For Les, a black man, the Warbury Estate in Hackney indexes real danger, for the hipsters and the blonde girls it does not (but perhaps it indexes coolness).

It is interesting to see how Les frames his talk about black culture and neighbourhoods in relation to hip hop. At the beginning of the extract (and many other times throughout the recording) Les is very explicit about the indexical links between hip hop and "the black culture and community" and "black people" (stave 5). From stave 5 to 23 Les does not mention hip hop explicitly, but just like in extract (1), there are some lexical items and other features of linguistic style that sustain the indexical ties with hip hop. Clearly the term hood in stave 12 is borrowed from hip hop, with possible alternatives in the UK context being end or road. In stave 22 Les is quoting what he imagines would be the reaction of the Warbury estates local residents or 'niggas'. Who( 's) dat has a long-standing history of indexing (stereotypical) black culture and speech and of course does so also phonologically (see also pronunciation of dhem ones dhere in stave 3). In hip hop and the genre of UK Grime, who's dat has been exploited in the context of gangsta, as, for example, the title of a recent song by London rapper Giggs attests. ${ }^{4}$ The indexical links to hip hop are of course particularly strengthened by the term nigga, but whereas this term remains indexical of in-group usage in hip-hop or black (youth) culture, the term goon for 'gangsta' is used more widely in UK youth vernacular. Other features of language style that are noteworthy include absence of to in "when you go Harlem" (stave 8) as well as multiple negation and use of ain't in "there ain't no white guy" (stave 8), all features that are now widespread in London vernacular. Framed by the explicit talk about hip hop and the use of cultural concepts indexing raced and classed hip-hop 'street' authenticity, these vernacular features become part of the tool kit employed by Les to index his membership in hip-hop culture.

In extract (3), taken from a section of the recording just prior to extract (2), Les continues to employ cultural concepts of place in the same way as above, but he is also more explicit about the link between 'understanding' (hip-hop) and black culture.

(3) I overstand the culture

1 Les: that's what it is now (.) like (.) white boys love hip hop more than niggas

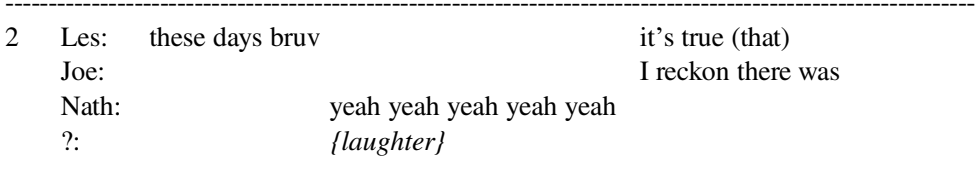

$\begin{array}{lll}\text { Les: } & \text { yeah } & \text { but now yeah } \\ \text { Joe: an impact as soon as hip hop came it was just like PSSCHH }\end{array}$

4 Les: you'll be you'll be in a club yeah and you'll have like (.) some white kid 
PIA PICHLER AND NATHANAEL WILLIAMS

5 Les: from like (.) flippin (3.0) what's it called \{laughter\} yeah

Nath: Peckham \{laughter\} Peckham now

6 Les: but Cambridge say Cambridge yeah Oxford

Joe: $\quad$ \{humorous\} craziest mutha fucka in Peckham (xxxx)

Nath: $\quad$ yeah

7 Les: $\quad$ some place you've never heard of bruv (.) where there ain't no niggas Nath: \{laughter\}

8 Les: there there ain't no flippin (.) Black community there there might be one

9 Les: black guy in the whole area and and they'll

Joe: it's the music and the fashion it's the whole (.) calling of

10 Les: sit down yeah and they'll tell you about they'll tell you the whole history of hip hop

11 Les: and they'll have their opinions and tell you why (.) they feel Biggie's better than

12 Les: *2Pac or vice versa and you know what I think Joe: $\quad$ (with) just as much substance to what you think

Nath: $\quad$ \{laughter\} yeah $(\mathrm{xxx})$

*hip-hop artists

13 Les: yeah to a certain extent that's all cool yeah (.) but I think yeah that (.) you

14 Les: see with that there comes yeah (.) like a (.) cer- like there's opinions going on

15 Les: now like $>$ not a lot going on there's always been opinions going on $<$

16 Les: there's always been opinions but in hip hop I feel like (.) there's

17 Les: a lot of people that don't understand the cul/ture (.) and

18 Les: tha- they make they pass judgement (.) on hip hop like you see me Joe: $\mathrm{mmm}$

19 Les: (.) like (.) I know yeah that $* 2$ Chainz chats shit I know Lil Wayne chats

*hip-hop artists

20 Les: a load of shit (.) /yeah but I understand the culture I overstand the culture=

21 Les: =do you know what I'm saying like

Joe: $\mathrm{mm} \quad$ you live the culture

Nath: $\quad$ yeah yeah 
22 Les: feel what I'm saying I live the culture so it's like p-people be like ah (.) Nath: yeah yeah yeah yeah yeah

23 Les: yeah he's just chatting rubbish deh deh deh deh deh but it's like if you

24 Les: I understand yeah where man's coming from the mentality

In this extract, Les authenticates himself in opposition to other (white, privileged) hip-hop fans. Les differentiates between those who love and/or who have knowledge of hip hop on one side, and those who 'understand', 'overstand', or even 'live' hip-hop culture. Again Les' authenticating work relies heavily on indexicalities of place, which in themselves are used to index class and race. This time it is not 'white girls from The Hills' but the 'white kids from... Cambridge' (or Oxford) who serve as an antithesis to hip-hop culture. It is interesting to observe how important the choice of specific place names is for Les. Whereas Nath offers Peckham to Les in his search for the right word in stave 5, Les rejects this offering (with considerable mitigation), introducing instead the place names of Oxford and Cambridge (stave 6). Clearly, the indexicality of Peckham, as a predominantly black and workingclass area (despite gentrification of some of its parts) does not convey the right macro-social meaning for Les. It is not only race, that is, 'white kids' but privileged/higher social class that he seeks to contrast with hip-hop authenticity here, relying on the associative meaning of Cambridge and Oxford as elite university towns. Joe's laughter in stave 7 indicates that there is some shared understanding of the stereotypic sociocultural meaning associated with these place names, and Les subsequently makes this level of meaning explicit in staves 78. In this extract, as in others before, it is noticeable that for Les race is intersected with social class and that it is used to signal (lack of) authenticity (see also Chun 2011).

The white kids may well love hip hop and understand the history of hip hop (as a music genre) so that they are able to talk about the quality of work of certain hip-hop artists, but Les is not prepared to grant them with 'understand[ing] the culture' (stave 17). When these white kids "pass judgement" (e.g. about 2Pac and Biggie) Les describes this as them "hav[ing] their opinions" (stave 11). Les, however, defends his own passing of judgment in stave 19-20 when he says that he "knows" that 2 Chainz and Lil Wayne "chat... a load of shit". Les positions himself as a qualified authority that can make these judgments because of his 'understanding' of the culture, which clearly goes beyond a mere knowledge of the music genre.

By using the lexical item overstand, which is frequently used in Rastafarian culture and indexes a fuller understanding, Les is able to legitimise his judgment of hip hop by positioning himself as an authentic member of black culture. In staves 20-22 Les's positioning is co-constructed by the group; he receives 
support from the others, for example, from Joe's suggestion "you live the culture" (stave 21) or Nath's minimal responses throughout. Overstand can thus be seen as a cultural concept indexing in-group membership in Rastafarian or black culture. Les's choice of the term appears conscious, as he first uses understand and then corrects to overstand. It is interesting that in the staves immediately following Les's self-correction to overstand, he also employs several features of language style that reinforce his self-positioning as an authentic and legitimate in-group member of black culture. In staves 21-22 "do you feel what I'm saying" is a form of you feel me, that is, "do you understand me", which appears borrowed from HHSS or HHNL (e.g. Alim 2009b:279). This is immediately followed by the use of habitual BE in "it's like p-people be like" in stave 22 (e.g. see Alim 2006:115). In stave 24 there is an example of man used as a pronoun, as discussed by Cheshire (2013) on the basis of some occurrences of the token in the speech of inner-city London youth from multi-ethnic friendship groups. ${ }^{5}$ Les is not the only person to use HHSS in this extract. In stave 6, Joe overtly voices but also parodies HHSS when he says "craziest mutha fucka in Peckham" in an instance of intertextuality which Roth-Gordon (2009:66-67) calls 'conversational sampling', that is, the recontextualisaion of rap lyrics into everyday conversation. This is followed by Les' "there ain't no niggas there", which could be seen as continuing the use of HHSS, although of course negative concord is widespread in many vernaculars. In this extract, the use of these features of language style can thus be seen to support the young men's use of cultural concepts that clearly highlight the significance of race (and class) for the authentication of the group (and in particular of Les), both in relation to hip hop and in relation to black culture more generally.

Although there is plenty of research that challenges the significance of race for the construction of hip-hop authenticity (Cutler 2003, 2009, 2010; Jeffries 2011), for this group of young men from a multi-ethnic/racial background, and in particular for Les, race remains a significant dimension of hip-hop authenticity and the group's authenticating work. ${ }^{6}$ Clearly, however, the local meanings of race in the two extracts above are very much intersected with social class. Moreover, extract (3) shows that the authenticity of what Peterson \& Kern (1996; see also Jeffries 2011:118) so poignantly call the 'cultural omnivore' - that is, middle class (and in our case 'white' young) consumers who now display knowledge of and participate in cultural practices that are not considered to be elite-is one that is challenged in the group.

INDEXICALITIES OF GANGSTA AND THUG L IF E

In extract (4), the group position themselves in relation to one of the most notorious aspects of hip-hop authenticity: 'thug life' (Jeffries 2011), inextricably linked to stereotypical black urban tough masculinities of the 'gangsta' or 'thug' (Kubrin 2005; Jeffries 2011; Nyawalo 2013). These performances of thug personas tend 
to go hand in hand with a foregrounding of a tough urban 'street' experience or even 'street code' (Kubrin 2005) and have become a central way for hip-hop artists to authenticate themselves or to demonstrate that they are 'keepin it real' (e.g. Cutler 2003, 2010; Terkourafi 2010a).

In many ways the 'thug' or 'gangsta' is an archetypal black hip-hop masculinity whose authenticity should be beyond doubt (see also Nyawalo 2013:462 on how the mythological characters of trickster and badman in African American folklore have influenced notions of authenticity in hip hop). Our recordings show, however, that 'gangsta' authenticity does not go entirely unchallenged in the group.

(4) Everyone's shook of man bruv

1 Les: Mike he's a bad yout bruv dey all bad you- his brother though (.)

2 Joe: who's that Ad- (0.4) I heard I heard stories in school blood

Nath: I was gonna say I heard stories

3 Les: $\quad$ =what=

Nath: I heard stories about that even me yeah= =stories about Biggy and like

4 Les: $\quad=$ =Adam don't play

Joe: $\quad$ his brothers are the ones blood

Nath: his brothers and like (xxxxxxxx)

5 Les: games bruv

Joe: $\quad$ I don't even like people talking to me in school (xxxxxxxxx)

6 Les: man say he's a little yout you know he's short like he's short he's

Joe: bus (xxxx)

Nath: $\quad(\operatorname{xxxxxxxxx)}$

7 Les: shorter than me like he's like your height maybe yeah but he's like (1.0)

Joe: $\quad \mathrm{hmm}$

8 Les: everyone's shook of man bruv

Joe: he's just a wild he's just a loose cannon innnit=

9 Les: $\quad$ yeah dhem man will spray the matic out da Porsche and

Nath: =just mad

10 Les: all dhem mad stories dhere you know all of them mad stories

Nath: $\quad$ \{laughter\}

11 Joe: yeah I heard shootouts just *as not even runnin

*cas[ually], not even running 
12 Joe: like it's some film (*bluv)

Nath:

laughter -) living in a film

*this sounds like a blend of blood and bruv

13 Les: y you you see Adam Adam will roll up yeah in a Phantom yeah (.)

14 Les: obviously it's a rental though but he will roll up in a
Joe:

15 Les: Phantom yeah with like with a mink coat on Joe: $\quad$ yeah with just $(\mathrm{xxxx})$

16 Les: yeah and a flippin (.) a crazy chain and a watch that's worth like 30

17 Les: bags (.) iced out *Roly or Jacobs or something stup- like (.) money’s lo:ng

*Rolex or Marc Jacobs

18 Les: bruv his money's long just long just long

Joe: $\quad$ and it's all road money 19 Les: all road money dhem man were like 15 they were coming in the
Joe: \{laughter\}

20 Les: shop stacks like dat dhem man were driving Mercedeses and that at like

21 Les: fiftteen when they couldn't even have a licence bruv dhem man are serious youts

22 Les: my brother chills with dhem man innit Nath: ${ }^{\circ}$ fucking hell mate ${ }^{\circ}$ wha- is i-

23 Les: my brother because my brother's a Peckham yout innit Joe: what's that ah OK

This extract contains a wealth of words and expressions that have become cultural concepts indexing gansta lifestyle, including (spray) the matic (automatic weapon) out da Porsche; shootouts; (roll up in a) Phantom (a particular type of Rolls Royce); mink coat; crazy chain; iced out Roly or Jacobs (designer watches decorated with 'bling'/diamonds); his money's long; and road money. The main protagonist of the story, Adam, is described by Les as somebody who "don't play games" (staves 4-5) and as "a little yout" (stave 6), who, despite his short stature, causes people to be afraid of him; "everyone's shook of man bruv" (stave 8) and his gang is described as "serious youts" (stave 21). Some of the words index violence and criminality, while others index a luxury lifestyle. All of them, however, are items that regularly feature in gangsta rap 
and hip-hop music videos where they have become flashy symbols of material success and streetwise toughness that authenticate the performance of gangsta identity.

Clearly, the stories in the extract suggest that Adam and his gang have managed to build the kind of violent 'rep' or street reputation that is at the centre of gangsta rap lyrics (e.g. Kubrin 2005:264, 372), and the retelling of the stories in this instance contributes to maintaining this reputation at the same time as allowing the group members to signal various degrees of affiliation or distancing. In addition to violence, it appears that the reputation of Adam and his gang is also connected to their (less convincing) efforts to signal their wealth in particularly exaggerated ways. Kubrin (2005:364) lists displays of wealth as another important way to 'gain respect' in addition to 'building a violent reputation' (see also Jeffries 2011:69 on theatrical and spectacular aspects of hip-hop authenticity).

The fact that Les's account of the actions of Adam and his gang is reminiscent of what we usually watch in a film is not lost on the group. In stave 12 Joe is the first to note "like it's some film (bluv)", followed by Nath "living in a film". Thus, although neither Joe nor Nath challenge the truth of the story, they both challenge the authenticity of the gangsta lifestyle of the story's protagonists to some extent. Les expresses a further, albeit slightly different challenge to the authenticity of the gangsta performances of Adam and his mates, by suggesting that the RollsRoyce Phantom in which the gang 'roll up' is actually rented rather than owned. The framing of the story also casts some doubt over its authenticity. All of the three speakers use a version of 'I heard stories' before Les launches into his main narrative about Adam and his gang brothers (see Joe in stave 2, Nath in staves 2-3, and Les in stave 10: "all dhem mad stories...").

Les does most of the authenticating work in this extract, by highlighting his own brother's membership in the notorious South London gang, the Peckham Boys ("my brother's a Peckham yout innit", stave 23) as well as by using a range of narrative, lexical, and phonological strategies. Already in stave 1 Les says of Mike and his gang, "he's a bad yout bruv dey all bad you-". Both yout and bruv are used throughout the extract, as are pronunciations of 'them' and 'they' as dem and dey. As we explained above, many of these features cannot be said to index membership in hip-hop culture in isolation. This is partly due to the fact that HHSS or HHNL draws on and is intertwined with black vernacular and culture (Alim 2006:100-116). The distinction between HHSS and Multicultural London English (Cheshire et al. 2011) is also far from clear, and HHSS does of course also contain local elements of language use, as many observers of code-mixing in multilingual rap have observed before (e.g. Pennycook 2007; Alim et al. 2009; Terkourafi 2010b).

There are multiple layers of authentication present in this extract. In their narrative Les and Joe use symbols such as the mink coat, the bling designer watch, the Rolls-Royce Phantom, or the automatic weapon to construct authentic 
gangsta identities for Adam and his gang members. At the same time the group challenges the authenticity of these tough gangstas to some extent. This challenge, just as much as Les's brother's gang membership, as well as the use of HHSS and MLE, and, above all, the insider knowledge of cultural concepts indexing thug life, all constitute important means of authentication for the group.

\section{O N C L U S I O N}

Our study was originally motivated by an interest in the spontaneous talk of young South London men. The data recorded by these young men from multi-ethnic, working-class backgrounds soon led us to appreciate the significance of hip-hop talk to the authentication and identification processes within this group. Our data contains many phonological, grammatical, and lexical markers that are indexical of Hip Hop Speech Style (Cutler 2003) or Hip Hop Nation Language (Alim 2006). As we argued throughout this article, however, the use of several of these language features is now widespread in the kind of London youth vernacular that has been captured by Cheshire and colleagues' (2011) work on Multicultural London English. Framed by the explicit but spontaneous hip-hop talk in our data and anchored by the cultural concepts that clearly index affinity to hip-hop culture, these features of linguistic style can, however, be seen as part of the group's authenticating tool kit. The precise relationship between HHSS and urban multi-ethnolectal speech styles such as MLE are beyond the scope of this article and warrant further investigation. As Brunstad and colleagues (2010: 237) argue on the basis of their work with young Norwegian hip hoppers who are also proud users of the local multi-ethnolect in Oslo: 'We believe that this combination of hip-hop affiliation with the use of a multi-ethnolect speech style is not coincidental'.

The main focus of our article has been on cultural concepts that index the group's cultural knowledge of and positioning towards not only hip hop, but also various other aspects of what Silverstein (2004) calls the 'macrosociological order'. The spontaneous interaction of the young men is very clearly organized in a 'conceptual metrics' (Silverstein 2004), which positions 'white posh girls from The Hills', 'hipsters moving into the hood', 'white boys from Cambridge', as well as the pop star Miley Cyrus in opposition to hip-hop culture. What is interesting is that many of these individuals take part in cultural practices that in themselves index allegiance with hip-hop or street culture, for example, by producing World Star Hip Hop videos, by moving to or living in the hood or in rough London estates, by having extensive knowledge about hip hop, or by 'twerking like a mutha fucka'. These attempts to index hip-hop or street authenticity, however, are not accepted by the group. The intersections of hip-hop authenticity stand out throughout the recordings. Race remains an important aspect of hip-hop authenticity in many moments of the talk, especially for Les. However, clearly race is intersected with social class and various other aspects of identity 
throughout. The white girls from The Hills are also 'posh', and both Miley Cyrus and the girl on the roughest estate in London have extremely rich and famous fathers. Place names such as Cambridge and Oxford function as cultural concepts indexing high social status, very much reminiscent of Silverstein's (2004) discussion of 'First world elite identities', which also included an example of speakers referring to university towns to position themselves and others. The indexical meaning of some of the cultural concepts (e.g. Cambridge, Oxford) may be understood more widely than that of others, such as 'Peckham yout'. Some cultural concepts are more recent and more specific to hip-hop culture, such as twerking and World Star Hip Hop. The group's authentication relies heavily on these cultural concepts and, as Silverstein (2004:633) argues, the use of cultural concepts 'marks (indexes) the user as a member of a certain group'. Despite the varying degrees of affiliation with hip-hop culture, and, even more so, thug life, explanations for the cultural concepts invoked are rarely necessary within the group. For example, everyone in the group understands that Les indexes street life in his colourful description of the local gang that includes reference to 'iced out Rolys or Jacobs', 'Phantom', 'road money', and 'spraying the matic out da Porsche'. The group's shared understanding of these and other words as cultural concepts indexing street life constitutes an important means of authentication in relation to hip-hop culture, which is presented as classed and raced in the 'microcontext of interaction' (Silverstein 2004) throughout the group's spontaneous hip-hop talk. The group's local authenticating practices thus draw on and engage also with larger-scale sociocultural meanings or, in Silverstein's (2004) words, the 'macrosociological order'. This should not come as a surprise as 'authenticity demands an account of matters beyond the self' (Pennycook 2007:103). An exploration of indexicalities on the basis of cultural concepts in the local context of spontaneous interaction can thus make a valuable contribution not only to research on authenticity in hip hop, but also to sociolinguistic studies of authentication more generally.

\section{A P P E N D IX: TR A N S C R P T I ON C O N V E N T IONS}

$\begin{array}{ll}? & \text { identity of speaker not clear } \\ \text { \{laughter\} } & \text { nonverbal or paralinguistic information } \\ (\text { xxxxx }) & \text { doubt about accuracy of transcription } \\ = & \text { latching on } \\ / & \text { rising tone } \\ (.) & \text { micropause } \\ (-) & \text { pause shorter than one second } \\ (1),(2) & \text { timed pauses (longer than one second) } \\ { }^{\circ} \text { word }^{\circ} & \text { reduced volume }\end{array}$




\section{PIA PICHLER AND NATHANAEL WILLIAMS}

\section{N O T E S}

*We would like to thank Les, Joe, and Tim for allowing us to write about their talk. We are also grateful to Sue Fox, Jen Coates, the editors, and the two anonymous reviewers for their comments on earlier drafts of this article.

${ }^{1}$ Tim does not feature in any of the four extracts that made the final edit of this article.

${ }^{2}$ The original title contained the words 'you are not ratchet pussy' from extract (1). The participants were concerned that in the title, taken out of context, the words would be associated with them rather than with Miley Cyrus who actually uttered these words. The young men were therefore concerned that the title would present them as sexist and reinforce a negative stereotype about young male hip-hop fans.

${ }^{3}$ Transcription is based on the stave system. Simultaneous speech is represented by vertically aligned utterances within one stave. Information in italics, marked with * at the bottom of each stave, explains some of the terminology used by the speakers in the group. Transcription conventions are listed in the appendix.

${ }^{4}$ Giggs (2015) Who's dat. SN1 RECORDS

${ }^{5}$ I would like to acknowledge Sue Fox for alerting me to the use of $\mathrm{man}$ as a pronoun in Multicultural London English.

${ }^{6}$ See also Roth-Gordon's (2009:70) work on the significance of the 'Black-White racial dichotomy' for the identification of Brazilian rappers and hip-hop fans.

\section{R E F E R E N C E S}

Alim, H. Samy (2006). Roc the mic right: The language of hip hop culture. New York: Routledge. (2009a). Straight outta Compton, straight aus München: Global linguistic flows, identities, and the politics of language in a global hip hop nation. In Alim, Ibrahim, \& Pennycook, 1-24. New York: Routledge.

(2009b). Hip hop nation language. In Alesandro Duranti (ed.), Linguistic anthropology: A reader. 2nd edn., 272-89. Oxford: Wiley Blackwell.

— youth identities, and the politics of language. New York: Routledge.

Androutsopoulos, Jannis (2009). Language and the three spheres of hip hop. In Alim, Ibrahim, \& Pennycook, 43-62. New York: Routledge.

Bourdieu, Pierre (1984). Distinction: A social critique of the judgement of taste. Trans. by Richard Nice. London: Routledge, Kegan \& Paul.

Bucholtz, Mary (1999). You da man: Narrating the racial other in the production of white masculinity. Journal of Sociolinguistics 3(4):443-60.

(2003). Sociolinguistic nostalgia and the authentication of identity. Journal of Sociolinguistics 7(3):398-416.

— \& Kira Hall (2005). Identity and interaction: A sociocultural linguistic approach. Discourse Studies 7(4-5):585-614.

Brunstad, Endre; Unn Røyneland; \& Toril Opshal (2010). Hip hop, ethnicity and linguistic practice in rural and urban Norway. In Terkourafi (ed.), 223-55.

Cheshire, Jenny (2013). Grammaticalisation in social context: The emergence of a new English pronoun. Journal of Sociolinguistics 17(5):608-33.

— — Paul Kerswill; Sue Fox; \& Eivind Torgersen (2011). Contact, the feature pool and the speech community: The emergence of Multicultural London English. Journal of Sociolinguistics 15(2):151-96.

Chun, Elaine (2011). Reading race beyond black and white. Discourse and Society 22(4):403-21.

Coupland, Nikolas (2003). Sociolinguistic authenticities. Journal of Sociolinguistics 7(3):417-31.

Cutler, Cecilia (2003). 'Keepin' it real': White hip-hoppers' discourses of language, race and authenticity. Journal of Linguistic Anthropology 13(2):211-33. 


\section{HIPSTERS IN THE HOOD}

(2009). Yorkville crossing: White teens, hip-hop and African American English. In Nikolas Coupland \& Adam Jaworski (eds.), The new sociolinguistics reader, 299-310. Houndmills, Basingstoke: Palgrave Macmillan.

(2010). 'She's so hood': Ghetto authenticity on the White Rapper Show. In Terkourafi (ed.), 300-328.

Durham, Aisha (2012). 'Check on it': Beyoncé, southern booty, and black femininities in music video. Feminist Media Studies 12(1):35-49.

Hewitt, Roger (1986). White talk black talk: Inter-racial friendship and communication amongst adolescents. Cambridge: Cambridge University Press.

Jeffries, Michael P. (2011). Thug life: Race, gender and the meaning of hip hop. Chicago: University of Chicago Press.

Kang, Agnes M. (2004). Constructing ethnic identity through discourse: Self-categorization among Korean American camp counselors. Pragmatics 14:217-34.

Kubrin, Charis E. (2005). Gangstas, thugs and hustlas: Identity and the code of the street in rap music. Social Problems 523(3):360-78.

Mason Carris, Lauren (2011). La voz gringa: Latino stylization of linguistic (in)authenticity as social critique. Discourse \& Society 22(4):474-90.

McLeod, Kembrew (1999). Authenticity within hip hop and other cultures threatened with assimilation. Journal of Communication 49:134-50.

Ochs, Elinor (1992). Indexing gender. In Alessandro Duranti \& Charles Goodwin (eds.), Rethinking context: Language as an interactive phenomenon, 335-58. Cambridge: Cambridge University Press.

Pennycook, Alastair (2007). Language, localisation, and the real: Hip hop and the global spread of authenticity. Journal of Language, Identity and Education 6(2):101-15.

-, \& Tony Mitchell (2009). Hip hop as dusty foot philosophy: Engaging locality. In Alim, Ibrahim, \& Pennycook, 25-42.

Peterson, Richard A., \& Roger M. Kern (1996). Changing highbrow taste: From snob to omnivore. American Sociological Review 61:900-907.

Rampton, Ben (1995). Crossing: Language and ethnicity among adolescents. London: Longman.

Reyes, Angela (2005). Appropriation of African American slang by Asian American youth. Journal of Sociolinguistics 9(4):509-32.

Roth-Gordon, Jennifer (2009). Conversational sampling, race trafficking, and the invocation of the gueto in Brazilian hip hop. In Alim, Ibrahim, \& Pennycook, 63-78.

Scott Shenk, Petra (2007). 'I'm Mexican, remember?' Constructing ethnic identities via authenticating discourse. Journal of Sociolinguistics 11(2):194-220.

Silverstein, Michael (2003). Indexical order and the dialectics of sociolinguistic life. Language \& Communication 23:193-229.

(2004). Cultural concepts and the language-culture nexus. Current Anthropology 45(5):621-52.

Terkourafi, Marina (2010a) Introduction: A fresh look at some old questions. In Terkourafi (ed.), 1-18. (ed.) (2010b). The languages of global hip hop. New York: Continuum.

Nyawalo, Mich (2013). From 'badman' to 'gangsta': Double consciousness and authenticity, from African-American folklore to hip hop. Popular Music and Society 36(4):460-75.

Weidhase, Nathalie (2015). 'Beyoncé feminism' and the contestation of the black feminist body. Celebrity Studies 6(1): 28-31.

(Received 21 August 2015; revision received 25 March 2016; accepted 11 April 2016; final revision received 22 April 2016) 